\title{
EXAMINATION OF SECONDARY METABOLITES AND ANTIOXIDANT CAPACITY OF ANTHYLLIS VULNERARIA, FUCHSIA SP., GALIUM MOLLUGO AND VERONICA BECCABUNGA SHORT COMMUNICATION
}

\author{
Rita Csepregi, ${ }^{1,2}$ Tímea BencsiK ${ }^{1}$ and Nóra Papp ${ }^{1 *}$ \\ ${ }^{1}$ Department of Pharmacognosy, University of Pécs, Rókus 2, H-7624 Pécs, Hungary \\ 2Department of Plant Biology, University of Pécs, Ifjúság 6, H-7624 Pécs, Hungary
}

(Received: April 1, 2016; accepted: May 6, 2016)

\begin{abstract}
Anthyllis vulneraria L., Fuchsia sp., Galium mollugo L., and Veronica beccabunga L. were selected to analyse the phenolic content and the antioxidant activity by ferric ion reducing antioxidant power (FRAP) and trolox equivalent antioxidant capacity (TEAC) assays. The highest polyphenol, tannin, and flavonoid contents were measured in Fuchsia species $(7.40 \pm 0.8,5.62 \pm 0.7$ and $0.72 \pm 0.1 \mathrm{~g} / 100 \mathrm{~g}$ dry weight), while the lowest values were detected in Anthyllis vulneraria $(0.68 \pm 0.02,0.17 \pm 0.03$ and $0.45 \pm 0.01$ $\mathrm{g} / 100 \mathrm{~g}$ dry weight) and Galium mollugo $(1.77 \pm 0.05,0.49 \pm 0.04$ and $0.16 \pm 0.06 \mathrm{~g} / 100 \mathrm{~g}$ dry weight). The leaf extract of Fuchsia sp. had the highest, while the herb of A. vulneraria had the lowest antioxidant effect measured by both methods, which is probably related to total polyphenol, tannin, and flavonoid contents.
\end{abstract}

Keywords: Antioxidants - FRAP - polyphenol - tannin - TEAC

Anthyllis vulneraria L., Fuchsia sp., Galium mollugo L. and Veronica beccabunga L. are used for various diseases in the local medicine of Transylvania, but until now there are only few data about their phytochemical composition. The leaves of Anthyllis vulneraria (Fabaceae) contain saponins, flavonoids (e.g. quercetin, kaempferol, isorhamnetin, rhamnocitrin, rhamnetin, tri-flavon, fisetin, and geraldol) $[6,10]$, anthocyanins, phenolic acids, carotenoids, and tannins [5, 7]. Anthocyanins (pelargonidin, cianidin, peonidin, malvidin) were detected in the flowers of Fuchsia sp. (Onagraceae), while in its leaves flavone glycosides (e.g. quercetin, kaempferol, apigenin, luteolin [3], kaempferol-3-glucoside, -galactoside, -rhamnose, and -arabinoside, quercetin-3-glucoside, -galactose, -rhamnose, -arabinoside, and -rutinosid, apigenin- and luteolin-7-glucuronide), diosmetin-7-glucuronide, and eriodictyol7-glucoside [18] were identified. In the aerial parts of Galium mollugo (Rubiaceae), there are flavonoids (hyperoside, rutin) [9, 14, 17], phenolic acids (chlorogenic acid, caffeic acid), phenylalanine propanoids, and iridoids [14, 17], while in Veronica beccabunga (Scrophulariaceae) chlorogenic acid, caffeic acid, luteolin and apigenin aglycones, and luteolin glycosides were detected $[11,16]$.

\footnotetext{
*Corresponding author; e-mail address: nora4595@gamma.ttk.pte.hu
} 
The relationship between the antioxidant activity of phenolic compounds and several diseases is controversial. Biological systems have different antioxidant mechanisms, which are able to neutralize free radicals and protect the cells against harmful effects. Antioxidants can be classified into two groups: enzymatic and non-enzymatic substances [15]. Non-enzymatic antioxidants (e.g. polyphenols) protect plants against oxidative damage such as ultraviolet radiation [13]. Reactive oxygen species (ROS) like superoxide anion, hydroxyl radical, and hydrogen peroxide are produced in vivo [2], which can be neutralized by antioxidant compounds [1]. Antioxidant efficiency of plants can be determined with various analytical methods, such as FRAP and TEAC, which are the most frequently used and reproducible analytical tests.

The aim of the work was to detect the polyphenol, tannin, and flavonoid contents of the selected four species, analyse their antioxidant activity by FRAP and TEAC assays, and find a relationship between the antioxidant effect and the presence of the specific metabolites.

The total polyphenol, tannin, and flavonoid contents were measured based on the spectrophotometric methods of the Hungarian Pharmacopoeia [8].

The FRAP method, which suitable for measuring the ferric reducing ability of plasma, is based on the reduction of a ferric 2,4,6-Tris(2-pyridyl)-s-triazine complex ( $\mathrm{Fe}^{3+}$-TPTZ) to ferrous form ( $\mathrm{Fe}^{2+}$-TPTZ), determined by the change of colour [4]. Samples were incubated at room temperature for $30 \mathrm{~min}$ and the change of the absorption was measured at $620 \mathrm{~nm}$ by a spectrophotometer (Shimadzu UV-1800). The calibration curve was prepared with ascorbic acid solution. The TEAC assay is based on the reduction of 2,2'-Azino-bis(3-ethylbenzothiazoline-6-sulfonic acid) diammonium salt as cation radical $\left(\mathrm{ABTS}^{+}\right)$[13]. The starting point of this method is that the synthetic $\mathrm{ABTS}^{-+}$cation radical is created by oxidizing ABTS using peroxidase and hydrogen peroxide. The solution has a strong greenish-blue colour, which fades after 15 min through the addition of the samples with antioxidant capacity. The process can be followed through the change of the absorption at $651 \mathrm{~nm}$. The calibration curve was prepared with trolox solution. FRAP values were given in $\mu \mathrm{mol}$ ascorbic acid, while TEAC values in $\mu$ mol trolox equivalent per $\mu \mathrm{g}$ leaf fresh weight.

Chemicals used for measurement of total tannin, total polyphenol, and flavonoid contents were the following: $\mathrm{AlCl}_{3}$ (Alfa Aesar), acetone, $25 \% \mathrm{HCl}$, ethyl acetate, $5 \%$ methanol-acetic acid (Molar Chemicals), distilled water, solution of $\mathrm{Na}_{2} \mathrm{CO}_{3}$ (LachNer), phosphor-molybdo-tungstic reagent (Sigma-Aldrich), pumice stone (Reanal), hide powder, hexamethylene tetramine, and pyrogallol (VWR). All chemicals used for FRAP and TEAC methods were purchased from Sigma-Aldrich. Trolox and gallic acid (used as standards) were dissolved in ethanol: water $(50: 50, \mathrm{v} / \mathrm{v})$.

The highest polyphenol and tannin contents were detected in the leaf extract of Fuchsia sp. (Table 1). We observed the lowest proportion of polyphenols and tannins in the herb of Anthyllis vulneraria, while their flavonoid content was relatively high. The other studied plants showed higher polyphenol and tannin contents. There was no significant difference between the flavonoid content of the studied species (Table 1). 
Table 1

Total polyphenol, tannin, and flavonoid content of the studied plants

\begin{tabular}{|l|c|c|c|}
\hline \multicolumn{1}{|c|}{ Plant samples } & $\begin{array}{c}\text { Total polyphenol content } \\
(\mathrm{g} / 100 \mathrm{~g} \text { drug })\end{array}$ & $\begin{array}{c}\text { Total tannin content } \\
\text { in pyrogallol }(\mathrm{g} / 100 \mathrm{~g} \text { drug })\end{array}$ & $\begin{array}{c}\text { Total flavonoid content } \\
\text { in hyperoside }(\mathrm{g} / 100 \mathrm{~g} \text { drug })\end{array}$ \\
\hline Anthyllis vulneraria & $0.68 \pm 0.02$ & $0.17 \pm 0.03$ & $0.45 \pm 0.01$ \\
\hline Fuchsia sp. & $7.40 \pm 0.80$ & $5.62 \pm 0.70$ & $0.72 \pm 0.10$ \\
\hline Galium mollugo & $1.77 \pm 0.05$ & $0.49 \pm 0.04$ & $0.16 \pm 0.06$ \\
\hline Veronica beccabunga & $2.75 \pm 0.90$ & $0.65 \pm 0.01$ & $0.44 \pm 0.03$ \\
\hline
\end{tabular}

The relatively high total antioxidant activity (TAC) values refer to the presence of antioxidant compounds in the selected plants (Fig. 1a). Among them, Fuchsia species had the highest, while Anthyllis vulneraria had the lowest values. The extracts of Galium mollugo and Veronica beccabunga showed higher values with FRAP assay

a

TEAC values

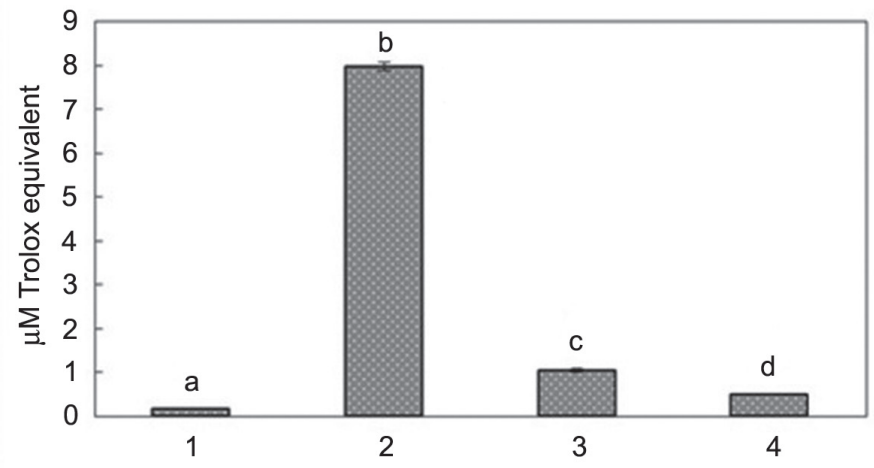

b

FRAP values

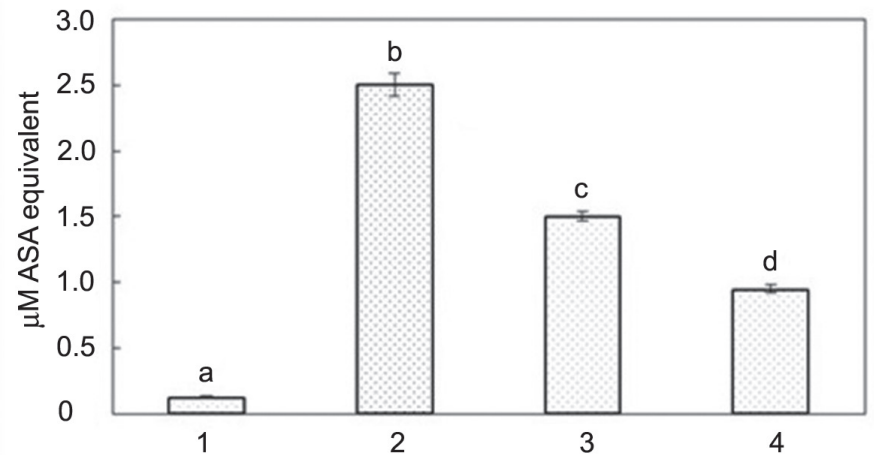

Fig. 1. Antioxidant activity of the selected plants studied by (a) TEAC and (b) FRAP assays. Plant samples: 1. Anthyllis vulneraria, 2. Fuchsia sp., 3. Veronica beccabunga, 4. Galium mollugo 
referring to the diverse character of the antioxidant compounds (Fig. 1b). By reason of the differences of both applied methods, further investigations are required. For statistical analysis, we used paired $t$-test, and we found significant differences in the measured values.

In this work, we measured the antioxidant capacity and some specific metabolites of four plants. Our results support the earlier data, that several polyphenols, tannins, and flavonoids can be found in A. vulneraria [5, 6], Fuchsia sp. [3], G. mollugo [9, 14], and $V$. beccabunga [16], and we found a relationship between the presence of the studied compounds and the antioxidant values. Fuchsia sp. showed the highest antioxidant values related to its high polyphenol, tannin, and flavonoid contents. Anthyllis vulneraria had the lowest polyphenol and tannin contents, while Galium mollugo had the lowest flavonoid content. These results require further qualitative determinations, e.g. with HPLC technique to obtain a broader overview on the antioxidant metabolites, and to identify the compounds which may be responsible for these effects in these species.

\section{ACKNOWLEDGEMENTS}

We are grateful for the kind help of the informants in the fieldwork, and for Éva Hideg and Kristóf Csepregi for their valuable instructions. This work was supported by grants from the OTKA (Hungarian Scientific Research Fund, PD 108534 and K112309).

\section{REFERENCES}

1. Agati, G., Brunetti, C., Di Ferdinando, M., Ferrini, F., Pollastri, S., Tattini, M. (2013) Functional roles of flavonoids in photoprotection: new evidence, lessons from the past. Plant Physiol. Biochem. 72, $35-45$.

2. Ali, S. S., Kasoju, N., Luthra, A., Singh, A., Sharanabasava, H., Sahu, A., Bora, U. (2008) Indian medicinal herbs as sources os antioxidants. Food Res. Int. 41, 1-15.

3. Crowden, R. K., Wright, J., Harborne, J. B. (1977) Anthocyanins of Fuchsia (Onagraceae). Phytochemistry 16, 400-402.

4. Firuzi, O., Lacanna, A., Petrucci, R., Marrosu, G., Saso, L. (2005) Evaluation of the antioxidant activity of flavonoids by "ferric reducing antioxidant power" assay and cyclic voltammetry. BBA Gen. Subj. 1721, 174-184.

5. Ghalem, M., Merghache, S., Ghalem, S., Belarbi, M. (2012) Phenolic contents and in vitro antioxidant activity of some secondary metabolites of Anthyllis vulneraria L. from Algeria. Int. J. Med. Pharm. Sci. 2, 51-64.

6. Gonnett, J.-F., Jay, M. (1972) Les aglycones flavoniques d'Anthyllis vulneraria. Phytochemistry 11, 2313-2316.

7. Hänsel, R., Keller, K., Rimpler, H. (1992) Hagers Handbuch der Pharmazeutischen Praxis. Springer Verlag, Berlin, Heidelberg, New York, London, Paris, Tokyo.

8. Hungarian Pharmacopoeia (2003) 8th ed. Medicina, Budapest.

9. Milić, P. S., Stanojević, L. P., Rajković, K. M., Milić, S. M., Nikolić, V. D., Nikolić, L. B., Veljković, V. B. (2013) Antioxidant activity of Galium mollugo L. extracts obtained by different recovery techniques. Hem. Ind. 67, 89-94.

10. Nartowska, J., Wawer, I., Strzelecka, H. (2001) Triterpenoid sapogenin from Anthyllis vulneraria. Acta Pol. Pharm. 58, 289-291. 
11. Nikolova, M., Berkov, S., Ivancheva, S. (2002) Determination of apigenin content in some Bulgarian Veronica species. Proceeding of the 7th Symposium on Flora of Southeastern Serbia and Neighbouring Regions, Dimitrovgrad, pp. 77-81.

12. Pandey, K. B., Rizvi, S. I. (2009) Plant polyphenols as dietary antioxidants in human health and disease. Oxid. Med. Cell. Longev. 2, 270-278.

13. Re, E., Pellegrini, N., Pannala, A., Yang, M., Rice-Evans, C. (1999) Antioxidant activity applying an improved ABTS radical cation decolorization assay. Free Rad. Biol. Med. 26, 1231-1237.

14. Tamas, M., Doina, S., Simina, T. (2006) Comparative phytochemical research of Galium verum L. and G. mollugo L. Not. Bot. Hort. Agrobot. Cluj 34, 18-20.

15. Valko, M., Leibfritz, D., Moncol, J., Cronin, M. T., Mazur, M., Telser, J. (2007) Free radicals and antioxidants in normal physiological functions and human disease. Int. J. Biochem. Cell Biol. 39, 44-84.

16. Wagner, H., Bladt, S. (1996) Plant Drug Analysis. Thin Layer Chromatography Atlas. Springer Verlag, Berlin, Heidelberg, New York.

17. Wichtl, M., Bisset, N. G. (1994) Herbal Drugs and Phytopharmaceuticals. Medpharm Scientific Publishers, Stuttgart.

18. Williams, C. A., Garnock-Jones, P. J. (1986) Leaf flavonoids and other phenolic glycosides and the taxonomy and phylogeny of Fuchsia sect. skinnera (Onagraceae), Phytochemistry 25, 2547-2549. 